Como citar este artículo en APA: Varo Pineda, F. (2019). Fe, razón y Teología en torno a la Historia Bíblica. Cuestiones Teológicas, 46 (106), 243-271. doi: http://doi.org/10.18566/cueteo.v46n106.a03

Fecha de recepción: 6 de julio de 2019 Fecha de aceptación: 2 de noviembre de 2019

\title{
FE, RAZÓN Y TEOLOGÍA EN TORNO A LA HISTORIA BÍBLICA
}

Faith, Reason and Theology on Biblical Historicity

Fé, razão e teologia a respeito da historia bíblica

Francisco Varo Pineda ${ }^{\mathrm{I}}$

1 Doctor Filología Bíblica por la Universidad Pontificia de Salamanca, España. Doctor en Teología por la Universidad de Navarra, España. Profesor ordinario de Antiguo Testamento (Sagrada Escritura), Facultad de Teología, Universidad de Navarra, España. Correo electrónico: fvaro@unav.es 


\section{Resumen}

La investigación acerca del marco histórico y del proceso de composición literaria de los textos bíblicos en las últimas décadas; ha seguido su propio camino, de ordinario al margen de la teología. Las metodologías utilizadas en ámbitos académicos y los resultados obtenidos hasta el momento plantean retos al teólogo y al pastor, en orden a discernir sus logros y a detectar sus limitaciones. En este artículo se ofrece una reflexión acerca de las conclusiones de estas investigaciones, orientada a plantear algunas sugerencias prácticas para la investigación bíblica y la docencia en el ámbito de la formación teológica.

Después de pasar revista a las aportaciones de los autores más significativos de las "historias independientes" del antiguo Israel y a las que se podrían enmarcar en el ámbito de la "tercera búsqueda" del Jesús histórico, se constata la configuración de algunos consensos, a la vez que se perciben las limitaciones de unos presupuestos metodológicos que, si solo aceptan como ocurrido lo que la común experiencia humana manifiesta como comprobable, cierran la puerta a realidades de orden superior, o presentan la figura de un Jesús al que no se deja ser ni Cristo ni Hijo de Dios.

Como conclusión se plantea la necesidad de cuidar un prudente equilibrio. De una parte, con una sabia apertura al menos a la posibilidad de que se hayan producido acontecimientos que, por su propia naturaleza, escapan a la comprobación empírica. De otra, evitando presentar como hechos reales lo que son lecturas literalistas del texto bíblico.

Palabras clave: Historia de Israel; Antiguo Testamento; Jesús histórico; Nuevo Testamento; Interpretación bíblica.

\section{Abstract}

Research regarding historical background and literary composition of biblical writings during the last decades has followed an independent path and has been done outside of theology. The methodologies used within the academic world and the results reached so far, pose challenges to theologians and clergymen regarding the identification of the actual achievements and limitations of such researches. Bearing this in mind, the article presents some considerations 
regarding the findings of those researches in order to outline some practical recommendations for biblical research and the teaching of theology. After reviewing the contributions of the most relevant researchers of "independent histories" of ancient Israel and those that could be labeled as the "third search" for historical Jesus, the emergence of some agreements is established, as well as the limitations of some methodological assumptions that, by accepting only what common human experience could prove, exclude some higher-order realities or present Jesus as a figure that cannot be either Christ or son of God. The conclusion is that a reasonable balanced should be encouraged. On the one hand, a healthy openness towards the possibility that some events have taken place that, because of their own nature, cannot be proved empirically. On the other, preventing to present as facts what are literal readings of the biblical writing.

Key words: History of Israel; Old Testament; Historical Jesus; New Testament; Biblical Interpretation.

\section{Resumo}

A pesquisa sobre o marco histórico e do processo de composição literária dos textos bíblicos nas ultimas décadas têm feito seu próprio caminho, geralmente nas margens da teologia. As metodologias usadas em âmbitos acadêmicos e os resultados conseguidos até hoje propõem desafios ao teólogo e ao pastor, no intuito de discernir seus avanços e distinguir suas limitaçóes. Nesse artigo se oferece uma reflexão sobre as conclusóes dessas pesquisas, orientada a propor algumas sugestôes práticas para a pesquisa bíblica e a docência na área de formação teológica. Depois de revisar as contribuições dos autores mais significativos das "histórias independentes" do antigo Israel e das que se poderiam situar na área da "terceira pesquisa" do Jesus histórico, constata-se a configuração de alguns consensos, ao mesmo tempo percebem-se as limitações de uns pressupostos metodológicos que, se solo aceitam o que a experiência comum humana manifesta tem por comprovável enquanto acontecido; eles fecham as portas às realidades de ordem superior ou apresentam a figura de um Jesus que não pode ser nem Cristo nem Filho de Deus. A conclusão propóe a necessidade de procurar um equilíbrio prudente. De uma parte, com abertura 
sabedora ao menos à possibilidade de ter produzido acontecimentos que, por sua própria natureza fogem à verificaçáo empírica. De outra parte, evita-se apresentar como dados reais o que são leituras literais do texto bíblico.

Palavras chave: Historia de Israel; Antigo testamento; Jesus histórico; Novo Testamento; interpretação bíblica.

\section{Introducción}

Se podría decir que, en los últimos cincuenta años, la investigación académica sobre la Biblia ha alcanzado un grado de sofisticación técnica tan compleja como la requerida por cualquier ciencia experimental. Desde tiempo atrás la exégesis bíblica se había caracterizado por un amplio diálogo interdisciplinar con campos de conocimiento tan diversos como la historia, la crítica textual y literaria, la papirología, la paleografía, la hermenéutica, la filosofía del lenguaje o la arqueología. Pero, en las últimas décadas, cada una de esas ciencias ha depurado extremadamente sus metodologías. Por ejemplo, actualmente la arqueología del próximo oriente no solo se interesa por las piedras y la cerámica sino que analiza en laboratorios los restos orgánicos disponibles para datar su antigüedad o para averiguar de qué especies eran los huesos encontrados en las ciudades, con el fin de determinar si aquellas gentes comían cerdo o solamente animales considerados puros por la legislación del Levítico (Maeir, 2014, p.62). Las reconstrucciones del pasado que se presentan parecen sólidamente fundadas en restos analizables, pero, a la vez, plantean no pocos problemas de difícil solución que con frecuencia hacen temblar los fundamentos de la fe en el lector sencillo de la Biblia.

En las páginas que siguen presentamos una síntesis del itinerario seguido por la investigación histórica acerca del mundo bíblico en los últimos años, así como algunos de sus resultados.

Primero hablaremos de los desarrollos de la historia antigua de Israel y sus relaciones con el texto bíblico. Después, pasaremos revista a la investigación histórica reciente en torno a la figura de Jesús de Nazaret. 
Seguidamente, señalaremos que las relaciones entre la historia y la composición de textos clásicos, también fuera de los estudios bíblicos, es objeto de interés en el mundo académico. Lo ilustraremos con un ejemplo referente a los estudios acerca de la composición de la Ilíada y la discusión acerca de si el contenido de esta obra guarda algún tipo de relación con acontecimientos reales que pudieran estar en la base de lo que se dice en sus cantos.

Ese análisis nos ayudará a valorar lo que está sucediendo en los estudios bíblicos. Además, nos preguntaremos hasta qué punto se pueden aplicar las mismas metodologías o en qué medida se requiere que esos métodos se corrijan o complementen para responder adecuadamente a la naturaleza propia de los textos de la Biblia.

En ese marco de referencia se plantearán unas reflexiones teológicas acerca de las relaciones entre fe y razón, especialmente en los ámbitos de la investigación, docencia y lectura de la Biblia, en las circunstancias actuales.

\section{El marco histórico del Antiguo Testamento en la investigación contemporánea}

Arqueología e historia bíblica se interesaron mutuamente en el siglo XIX. En la Biblia hay multitud de relatos enmarcados en la geografía de Palestina y las tierras del Próximo Oriente, en épocas pretéritas. Así, en las primeras excavaciones llevadas a cabo en esas regiones, parecía posible que se pudiesen encontrar en la Biblia algunas noticias que dieran razón de los hallazgos arqueológicos y, al contrario, que los propios hallazgos sirvieran para ayudar a comprender mejor algunos puntos oscuros de las narraciones contenidas en la Biblia. De este modo, se comenzaron a confrontar datos bíblicos y hallazgos arqueológicos, pasando de un optimismo generalizado en la primera mitad del siglo pasado al surgimiento de perplejidades cada vez mayores antes detalles que no terminaban de encajar (Varo, 1995, pp.752-783).

En efecto, los intentos por compaginar los restos arqueológicos con lo narrado en los textos bíblicos se fueron encontrando con numerosos problemas, no solo en lo relacionado con los relatos acerca del origen del pueblo, como 
los patriarcales o el éxodo, sino también en lo que se cuenta acerca de la época monárquica (Varo, 2013, pp.167-172). También, los diferentes niveles de desarrollo que se han observado, en momentos contemporáneos, entre las regiones del centro y del norte de Israel con respecto a la región meridional, plantean interrogantes acerca de la existencia de una monarquía unida que gobernase todos esos territorios (Varo, 2013, pp.230-231). De ahí surge la duda acerca de si, entre el reino de Israel, floreciente en los siglos IX y VIII a. C. en el centro y el norte (Campbell, 1998; Faust, 2000), y el de Judá, que comenzó a tener alguna importancia en el siglo VII a.C. en la región del sur (Dalley, 2004; Faust \& Weiss, 2005), hubo una relación étnica, social, religiosa o económica mayor que la que pudo haber entre otros reinos vecinos como Siria, Moab o Edom. De hecho, si se atendiera solo al retrato de la época que muestra la arqueología, no estaría claro que Israel y Judá procedieran de la partición de una monarquía unitaria como la que el relato bíblico presupone en torno a las figuras de Saúl, David y Salomón, ya que el origen de ambos reinos sería perfectamente explicable como consecuencia de un desarrollo propio de cada región en paralelo. ¿¿l reino de David y Salomón, entonces, es una mera creación literaria, o responde a una estructura política real que existió unida en algún momento y luego se fragmentó?

De otra parte, las discordancias entre las dataciones que se proponen para ciertas construcciones -como, por ejemplo, los llamados "establos de Salomón” en Meggidó- a partir de la cerámica y la estratigrafía, con respecto a las fechas que correspondería adscribirles si se sigue la cronología de la Biblia, también han sido fuente de conflictos.

Ante este tipo de problemas en la confrontación de los datos bíblicos y extrabíblicos, en los años 80 del siglo pasado, se fue abriendo paso la opinión de que sería conveniente prescindir de lo que cuenta la Biblia en la interpretación de los hallazgos arqueológicos y utilizar solamente los restos epigráficos contemporáneos a los demás vestigios hallados en las excavaciones. En realidad, es lo que se hace cuando se escriben historias de Egipto, Asiria o Babilonia. Se trataría de utilizar, en los estudios sobre la historia de Israel, la misma metodología que en los demás pueblos de la época, y, por lo tanto, de prescindir de la Biblia. 
Desde estas nuevas coordenadas, comenzaron a componerse entonces las que, siguiendo a Lemche (1985), se han denominado "historias independientes", e incluso, de manera más provocadora, "historias independientes de Palestina" (Whitelam, 1996). Este modo de trabajar se fue generalizando, al punto que en los últimos veinte años casi todas las historias que se han publicado en ámbitos académicos son de este tipo (Varo, 2013, pp.170-172 y 180-185).

Los autores más característicos de esta tendencia son Thomas L. Thompson (1992), Gösta W. Ahlström (1993), y los ya citados Niels Peter Lemche (1985 y 1998) y Keith W. Whitelam (1996), a los que se podría añadir, ya que se mueven con análogos presupuestos, Diana V. Edelman (1993), Mario Liverani (2003) y Philip R. Davies (2008). Los arqueólogos con los que parecen congeniar mejor son Amihai Mazar y, sobre todo, Israel Finkelstein (Finkelstein \& Mazar, 2007). En cualquier caso, no se trata de un grupo monolítico ni su percepción de la historia es uniforme, pues hay notables diferencias entre ellos. Lo que les caracteriza es, más bien, una común actitud de independencia frente a lo que diga el texto bíblico a la hora de afrontar la historia. Algunos otros, como J. Alberto Soggin (2002), autores de importantes historias de Israel, aprecian las aportaciones de estas "historias independientes" aunque no siempre comparten sus conclusiones.

Después de algo más de dos décadas de trabajo en esa línea, jes muy distinto el panorama que presentan esas "historias independientes" del que ofrecen los textos bíblicos? Digamos que, aunque en las épocas más pretéritas no faltan discordancias, estas son menores, a medida que hablamos de épocas más tardías.

El primer momento en que la ciencia histórica comienza a dibujar un paisaje que puede servir de marco a los relatos bíblicos es el periodo que los arqueólogos denominan de transición entre el Bronce Reciente y el Hierro. Las excavaciones muestran, en ese momento, una sociedad campesina que poco a poco se va estructurando en clanes, una vez que las ciudades estado han perdido el poder que tenían en los siglos XIV-XIII a.C. como consecuencia de los grandes cambios provocados por la creciente sequía, especialmente con el empuje de los pueblos del mar. Este marco histórico 
puede constituir el substrato social que está en la base de los relatos sobre los Jueces (Chaney, 1983; Finkelstein, 1996; Joffe, 2002 y, sobre todo, las dos obras coordinadas por Grabbe, 2008 y 2010). En esa época, la estela de Merenptah menciona por primera vez a un grupo humano al que se denomina Israel, y que parece designar a unos nómadas que peregrinan por las regiones centrales de Palestina (Kitchen, 2004).

Las primeras menciones a personajes bíblicos datan del siglo IX a.C., proceden del norte y son alusiones a la "casa de Omrí". El primer rey del que se conoce su nombre fuera de la Biblia es Ajab de Israel (Hallo, 1997, COS 2.113A, II. 86b-102).

También se ha encontrado una alusión a la "Casa de David” en la inscripción de Tell Dan, de la segunda mitad del siglo IX a.C., aunque no está hablando de ese rey sino de Jazael de Damasco y de la muerte en Yizreel de un rey de Israel (Joram, hijo de Ajab) y alguien de la "casa de David" (Ocozías de Judá). Estos hechos acaecieron probablemente en el año 841 a.C. (Galil, 2001).

Mientras existió, fue mucho más poderoso el reino de Israel, con su capital Samaría, que el de Judá, gobernado desde Jerusalén. Se conocen por inscripciones de la época los nombres de algunos reyes de Israel (Ajab, Jehú, Joás, Menájem, Pécaj y Oseas, poco antes de la conquista de Samaría). El primero de Judá que se menciona fuera de la Biblia es Ajaz, que paga tributo a Tiglatpileser III (729 a.C.). En realidad, parece que el reino de Judá solo comienza a contar con cierta relevancia internacional a partir de entonces, e incluso un poco después, gracias al impulso de Ezequías. En los documentos extrabíblicos hay referencias a Ezequías, Manasés y, finalmente, Yoyaquín, que fue llevado al destierro de Babilonia (Varo, 2013, pp.235241 y 260-269).

El regreso de los deportados y la reconstrucción de Jerusalén son perfectamente coherentes con la política imperial persa a partir de Ciro el Grande. Las misiones de Esdras y Nehemías, aunque se debate sobre su datación y el orden en que tuvieron lugar, también encajan bien en ese momento que, por otra parte, ofrece un marco histórico que ayuda a comprender la sociedad judía de la época, con una estructuración que 
explica de modo bastante coherente muchas de las cuestiones literarias del Pentateuco y otros libros que, posiblemente, fueron alcanzando en esos momentos su forma definitiva (Lipschitz \& Oeming, 2006; Heltzer, 2008).

La época helenística y luego la romana están mucho mejor documentadas históricamente y es posible enmarcar en ellas tanto relatos de base histórica, como los libros de los Macabeos, recopilación de textos poéticos y sapienciales (Collins \& Sterling, 2001; Doran, 2011).

En síntesis, se podría decir, a muy grandes rasgos, que los marcos que dibujan las "historias independientes" no presentan grandes contradicciones con los relatos bíblicos (siempre que estos se interpreten correctamente, atendiendo a los géneros literarios y modos de expresión empleados, no en una ingenua lectura literalista) aunque sí dejan épocas marcadas con grandes silencios. A medida que se trata de relatos sobre épocas más antiguas, cada vez es más difícil encontrar un apoyo en restos arqueológicos de lo que cuentan los textos de la Biblia. Por ejemplo, es indudable la existencia de Ezequías y el impulso reformista de su reinado en torno al año 700 a.C. Si retrocedemos trescientos años, en el contexto de una "historia independiente" solo se puede afirmar que hubo un personaje llamado David que dio origen a una dinastía asentada en Judá. Pocos siglos antes, es verosímil para ese tipo de historias el que un grupo de trabajadores escapados de Egipto fueran llegando y asentándose entre el Jordán y el Mediterráneo. Acerca de eventuales familias de pastores nómadas, como podrían ser los clanes patriarcales que, con siglos de antelación, recorrían aquellas tierras con sus ganados, esas historias no pueden decir nada, a falta de vestigios materiales que, a día de hoy, lo atestigüen.

¿Se podrían completar esas lagunas de información que dejan las ausencias de evidencias arqueológicas con lo que cuentan los textos bíblicos? Si, como dice Benedicto XVI (2010, n. 32), la historia de la salvación por ser verdadera historia hay que estudiarla "con los métodos de la investigación histórica seria”, conviene ser muy prudentes. Hace más de dos mil ańos los modos de exponer la realidad no se ajustaban a las formalidades de lo que hoy requiere el lenguaje técnico de la historia, por lo que antes será necesario sopesar los géneros literarios que se están empleando en cada caso para hacerse cargo de lo que se 
quiere decir. Pensemos, por ejemplo, en las genealogías de los hijos de Noé, que muestran, sobre todo, la geografía humana de la zona y los parentescos populares entre los pueblos entonces conocidos (Knoppers, 2003; Darshan, 2013), pero no pretenden ofrecer un elenco detallado de nombres de personas con sus grados exactos de parentesco.

De ordinario, los historiadores profesionales, por los motivos antes expuestos, prefieren callar sobre lo que no se puede tener una certeza racional.

\section{El acceso histórico a Jesús en la investigación contemporánea}

En el apartado anterior hemos repasado los hitos más importantes en la investigación contemporánea sobre cuestiones acerca de la relación entre el Antiguo Testamento y la historia común. Las mismas ideas de fondo y metodologías análogas se han aplicado al estudio de Nuevo Testamento y a su contexto histórico. Por eso, ahora vamos a ocuparnos de estas cuestiones. Primero presentaremos un acercamiento rápido al progreso de la investigación histórica sobre Jesús, prestando atención a sus aportaciones y límites. Luego, compartiremos algunas reflexiones sobre la situación actual.

Durante bastante tiempo la mayor parte de los cristianos han estado convencidos de que se conocían con certeza muchos pormenores de la vida de Jesús. Sin embargo, el desarrollo de la investigación crítica a lo largo de los últimos siglos, sumado a la reciente difusión acrítica de hipótesis sensacionalistas, han puesto un manto de duda sobre el acercamiento piadoso a su figura. Desde finales del siglo XIX, en efecto, se fue enfriando la fe sencilla de mucha gente del común ante el planteamiento radical de una cuestión que ya venía de lejos en el ámbito académico: ¿es posible conocer algo acerca de la existencia de Jesús, sobre su vida y su predicación original? Responder a esta pregunta no es tarea simple.

En las publicaciones actuales, al exponer el status quaestionis acerca de esta investigación histórica, se ha vuelto corriente hablar de la cuestión 
del "acceso a Jesús" para designar la búsqueda llevada a cabo con una metodología racional, histórico-crítica y literaria, de los datos que se pueden conocer con certeza humana, puramente racional y sin contar con la fe, acerca de Jesús de Nazaret. En nuestros días, es habitual sintetizar las etapas más significativas de esa búsqueda en cuatro periodos: "primera búsqueda", "no búsqueda", "nueva búsqueda" y "tercera búsqueda". Como se trata de una historia bien conocida y sobre la que hay buenas exposiciones sintéticas (Segalla, 1993), nos limitamos ahora a señalar los hitos más relevantes de la "tercera búsqueda", que es la que continúa más activa en nuestros días.

En los años setenta del siglo pasado, especialmente a partir de los estudios de Gerd Theissen (1985, 1988 y 2003), se abrió una línea de investigación que se interesaba por las condiciones sociológicas que propiciaron la composición y transmisión de los textos neotestamentarios. Esto fue posible, en gran medida, gracias al mayor y mejor conocimiento de las fuentes evangélicas y de su contexto judío y helenista, y permitió encuadrar mejor el ministerio de Jesús en el ambiente judío del siglo I. Desde estas nuevas perspectivas se fue suscitando un renovado interés por la búsqueda del Jesús histórico que, a partir de los años ochenta, ha sido caracterizado como la "tercera búsqueda".

La denominación "tercera búsqueda" fue introducida por Nicholas Thomas Wright (1988) para designar el tipo peculiar de búsqueda del Jesús histórico, que se da a finales del siglo xx y que considera a Jesús como profeta escatológico al mismo tiempo que subraya su posición dentro del judaísmo del siglo I. Para Wright, la "nueva búsqueda" y la "tercera" coexisten, aunque en los últimos años el término ha pasado a ser utilizado de manera genérica para referirse a todos los estudios recientes sobre Jesús, independientemente de la perspectiva que adopten.

Una primera línea de aportaciones son las que llegan desde el nuevo conocimiento del mundo judío "intertestamentario". De una parte, los escritos de Qumrán testimonian el pluralismo que existía en el judaísmo de los tiempos de Jesús. También los apócrifos del Antiguo Testamento están ayudando a conocer el sustrato judío en el que, a finales del siglo I, surgiría el cristianismo por un lado, y el judaísmo rabínico por otro. La variedad de 
textos pone de relieve la vitalidad de la religión judía en tiempos de Jesús. De otra parte, el mejor conocimiento de otras fuentes judías, sobre todo lo referente a la obra de Flavio Josefo, ofrece algunas contribuciones de notable interés. En buena medida, como consecuencia de estas aportaciones, han sido numerosas las obras recientes donde se acentúa el carácter judío de Jesús. Entre ellas se podrían situar las de Ben Witherington (1994), Geza Vermes (1996), y Nicholas Thomas Wright (1996).

Una segunda línea de investigación abierta, con notables aportaciones, es la que deriva del nuevo conocimiento del mundo grecorromano. El uso de fuentes de ese ámbito ha permitido mejorar el conocimiento del ambiente helenístico que se vivía en buena parte de la Palestina del siglo I. El estudio de los papiros mágicos griegos, por ejemplo, ha servido para ilustrar la religiosidad popular del mundo mediterráneo: actitud ante las enfermedades, demonios, espíritus malignos y benignos, o uso de amuletos. Los textos retóricos grecorromanos -en especial los Progymnasmata de Theón-, que enseñan muchos aspectos de la educación helenística y de las escuelas filosóficas griegas, también han puesto de manifiesto un tipo de educación muy extendida por todo el Mediterráneo, en el que los predicadores itinerantes ocupaban un puesto destacado. Autores significativos de esta línea son Morton Smith (1978), que ve a Jesús como un mago y, sobre todo, las de Gerald Downing (1988) y Burton Mack (1993), que vinculan, cada uno a su modo, la figura de Jesús con las de los filósofos itinerantes cínicos.

Otra perspectiva importante proviene del empleo de textos no canónicos como fuentes para el estudio del Jesús histórico. Se incluyen aquí los apócrifos del Nuevo Testamento y los códices de Nag-Hammadi (biblioteca gnóstica que apareció en Egipto en 1945). Para algunos autores cobran especial importancia el evangelio apócrifo de Pedro, el papiro Egerton (hipotético Evangelio de la Cruz) y, a raíz de su aparición en Nag Hammadi, el Evangelio de Tomás, el de Felipe y el Apócrifo de Juan. Uno de los autores más prolíficos y cuestionados, John Dominic Crossan (1991 y 1994), otorga a estas fuentes una gran relevancia. Para Crossan, que también se inclina por una imagen de Jesús análoga a la de los filósofos itinerantes cínicos, Jesús habría sido un reformador social, encuadrado en la cultura mediterránea rural, cuyo programa de igualitarismo radical acabó, por accidente, con su muerte en la cruz. 
En continuidad con los estudios sociológicos sobre el Nuevo Testamento, habría que mencionar la aplicación de los métodos de la antropología cultural a la investigación sobre Jesús. En esta línea se podrían encuadrar los trabajos de Marcus Borg (1994), quien presenta la figura de un Jesús no mesiánico, hombre espiritual, que propugnó una visión social alternativa, y los de Richard Horsley (2003), para quien Jesús fue un profeta social.

Puesto que en los relatos evangélicos abundan las narraciones de milagros realizados por Jesús, muchos autores se han sentido especialmente atraídos a investigar esos relatos. En vez de considerarlos burdas invenciones de la Iglesia primitiva para resaltar lo sobrenatural de Jesús, como los habían considerado los autores de la "primera búsqueda", estudian esos relatos en el contexto de las narraciones sobre taumaturgos y curanderos en el judaísmo y helenismo de la época. En consecuencia, según otras presentaciones de la vida de Jesús, este habría sido visto por sus contemporáneos preferentemente como un sanador, un mago o un exorcista (Twelftree, 1993).

E. P. Sanders (2001), que realizó un notable esfuerzo por enraizar a Jesús en el judaísmo y a la vez dar razón de la aparición de un movimiento judío formado en torno a su figura y que acabó desgajándose del judaísmo, lo presenta como un profeta, un enviado de Dios para llevar a cabo la restauración escatológica de Israel. Por su parte, John P. Meier (1998-2017) enriquece algo más esta presentación señalando que, además de anunciar el Reino de Dios -realidad en parte ya presente, pero también con un carácter trascendente que habría de irrumpir plenamente en un futuro no lejano-, fue exorcista y taumaturgo, y estuvo dotado de una autoridad carismática.

En síntesis, las presentaciones de la vida de Jesús que se han ido publicando en los últimos años son muy variadas, ya que se afrontan desde muy diversas orientaciones. A la pregunta sobre quién fue Jesús realmente, en especial a los ojos de sus contemporáneos, se han dado, pues, respuestas muy variadas, muchas veces contradictorias o, al menos, difícilmente conciliables entre sí. Se ha dicho casi de todo acerca de él: que era un rebelde político, campesino reformador, taumaturgo piadoso, rabino apocalíptico, profeta apocalíptico, apocalíptico no sectario, milenarista ascético, fariseo ortodoxo, curandero mágico, curandero carismático, fariseo seguidor de Hilel, maestro carismático y marginal, campesino judío y predicador 
cínico, profeta escatológico, hombre del Espíritu. Se lo ha presentado como un revolucionario antirromano que luchaba por derrocar a los poderes establecidos y fracasó, o como un moralista bondadoso que acoge a todos los marginados y proscritos y que, incomprensiblemente, termina por causar su propia ruina. Aunque es casi imposible presentar una sistematización de las diversas propuestas, si hubiera que sintetizar en pocas palabras todos los rasgos de su perfil, tal vez se podría afirmar que, de acuerdo con la imagen que presentan los estudios contemporáneos, Jesús fue un judío marginal, reformador social procedente del campo galileo, profeta escatológico itinerante, sabio y carismático.

Ahora bien, ¿es eso lo que puede decirse de Jesús, desde el punto de vista histórico? Ante unas propuestas tan variadas, la impresión general es que, en realidad, es bien poco lo que se sabe y mucho lo que se imagina cuando se intentan integrar unos datos fragmentarios de un modo atractivo. De hecho, muchos desarrollos de la investigación contemporánea sobre Jesús están plenamente imbuidos de la lógica postmoderna.

En un contexto cultural en el que se pone en duda la existencia de verdades objetivas e inmutables, en el que solo se acepta que puede ocurrir lo que en la experiencia se comprueba que ocurre, y en el que se excluye lo que solo es inteligible desde Dios, si se busca presentar un Jesús que sea comúnmente aceptable, cabe el peligro de ofrecer la figura de un Jesús al que no se deja ser ni Cristo ni Hijo de Dios. Detrás del entusiasmo de algunos por la figura de un Jesús sanador, inconformista, revolucionario social o líder carismático, late el atractivo por lo humano.

Si en nuestros días, incluso el teólogo, siempre atento a presentar el mensaje cristiano de modo que pueda ser bien acogido por sus coetáneos, puede sentir reparo en presentar abiertamente a Jesús como el Hijo Unigénito de Dios que se ha hecho hombre, como si de este modo su figura se alejara de las mujeres y hombres de hoy, no debe causar admiración que el mero historiador se haya podido detener a cierta distancia del núcleo fundamental. Tal vez en la "tercera búsqueda", a pesar de sus innegables aportaciones, se haya planteado la delimitación del personaje Jesús como un ejercicio académico de análisis literario, enmarcado en algunas coordenadas históricas, 
pero no se ha prestado atención suficiente a la pregunta fundamental: ¿quién fue Jesús?

Es mucho lo que nos hemos acercado al perfil histórico de Jesús, pero ¿basta con eso?, ¿qué aportan esas reconstrucciones históricas al conocimiento del personaje real que fue Jesús, si no afronta de veras la cuestión de su naturaleza íntima? ¿Es el Hijo de Dios hecho hombre, como confiesa la Iglesia, o es un simple hombre y nada más? No son preguntas a las que pueda responder la historia, pero no son cuestiones de las que el historiador riguroso pueda prescindir.

Un camino interesante para abordar esta cuestión es el que Joseph Ratzinger propone, con sencillez y sentido común, en su obra Jesús de Nazaret. Analizando las fuentes cristianas más antiguas, los escritos del Nuevo Testamento y aun reconociendo que su presentación de Jesús está ciertamente mediada por la fe, invita a reflexionar sobre el inesperado éxito de un crucificado:

Solo si ocurrió algo realmente extraordinario, si la figura y las palabras de Jesús superaban radicalmente todas las esperanzas y expectativas de la época, se explica su crucifixión y su eficacia. Apenas veinte años después de la muerte de Jesús encontramos en el gran himno a Cristo de la Carta a los Filipenses (cf. Flp 2,6-11) una cristología de Jesús totalmente desarrollada, en la que se dice que Jesús era igual a Dios, pero que se despojó de su rango, se hizo hombre, se humilló hasta la muerte en la cruz, y que a Él corresponde ser honrado por el cosmos, la adoración que Dios había anunciado en el profeta Isaías (cf. Is 45, 23) y que solo Él merece. La investigación crítica se plantea con razón la pregunta: ¿Qué ha ocurrido en esos veinte años desde la crucifixión de Jesús? ¿Cómo se llegó a esta cristología? En realidad, el hecho de que se formaran comunidades anónimas, cuyos representantes se intenta descubrir, no explica nada. ¿Cómo colectividades desconocidas pudieron ser tan creativas, convincentes y, así, imponerse? ¿No es más lógico, también desde el punto de vista histórico, pensar que su grandeza resida en su origen, y que la figura de Jesús haya hecho saltar en la práctica todas las categorías disponibles y solo se la haya podido entender a partir del misterio de Dios? Naturalmente, creer que precisamente como hombre 
Él era Dios, y que dio a conocer esto veladamente en las parábolas, pero cada vez de manera más inequívoca, es algo que supera las posibilidades del método histórico. Por el contrario, si a la luz de esta convicción de fe se leen los textos con el método histórico y con su apertura a lo que lo sobrepasa, éstos se abren de par en par para manifestar un camino y una figura dignos de fe (Ratzinger, 2007, pp. 18-19).

En esta obra, Ratzinger hace una aportación relevante que ofrece pistas de investigación hasta ahora poco exploradas. Son aquellas que invitan a afrontar el trabajo con la solidez contrastada de las más modernas metodologías históricas, con fuerte interdisciplinariedad, como es característico en los trabajos de la "tercera búsqueda", pero con plena apertura a esa realidad que sobrepasa la materialidad de los textos y los abre de par en par a una visión más cabal de la realidad. También ahora se requiere estudio serio y ponderación para llegar a resultados solventes, que se contemplan como posibles.

\section{Textos antiguos e historicidad, en la investigación académica actual}

Un fenómeno análogo al que acabamos de describir sobre las relaciones entre la investigación histórica contemporánea y los textos bíblicos, tanto del Antiguo como del Nuevo Testamento, se viene produciendo también en torno a otros textos antiguos que han tenido un fuerte impacto en la configuración de la cultura greco-latina. La pregunta por la historia es muy relevante, y no por motivos teológicos, en el estudio académico de los textos clásicos que más han influido en la cultura humana.

Un ejemplo paradigmático lo constituyen los estudios académicos sobre la Ilíada, que, como es sabido, se trata de la obra con más amplia tradición textual y literaria de la humanidad después de la Biblia. De ella se conservan unos seiscientos cincuenta manuscritos, mientras que -puede dar idea de la magnitud de la importancia del poema homérico- de los Anales de Tácito hay veinte copias anteriores a la imprenta. Los manuscritos bíblicos en griego superan los cinco mil. 
Desde hace unas décadas se han multiplicado las publicaciones de estudios específicos sobre la relación entre la Ilíada y la historia, y son centenares las consideraciones sobre el tema que se incluyen en las ediciones más recientes de esta obra (Kelly, 2006; Petrakis, 2006; Grethlein, 2008).

En esas investigaciones se refleja de modo bien claro que el debate sobre la historicidad de lo cantado por Homero está muy vivo desde hace más de cincuenta ańos. Desde entonces no se ha dejado de comparar el mundo reflejado en los poemas homéricos con las realidades documentadas por los datos arqueológicos.

De una parte se observa, desde el punto de vista literario, que las informaciones que proporcionan las diversas secciones de la obra, y especialmente el llamado "Catálogo de las naves", son a veces contradictorias entre sí, y también lo son en mayor o menor medida con los datos atestiguados por la arqueología. Todo hace pensar, por ejemplo, que en el "Catálogo de las naves" estamos ante una pieza que al principio era independiente, pero fue añadida a la Ilíada en un momento posterior. Esta y otras inconsistencias del texto han de ser tomadas seriamente en consideración al plantearse la cuestión de la historicidad básica del poema.

Por otra parte, la llamada "arqueología homérica", que en la primera mitad del siglo XX parecía ilustrar bastante bien el mundo de la Ilíada y la Odisea, con el paso de los años y con el empleo de elementos más afinados de datación y valoración de los restos arqueológicos ha entrado en crisis, ya que hay muchos detalles que deben ser revisados. Algunos autores, como Oliver Dickinson (2010), han llegado a cuestionar la existencia de verdaderas relaciones entre el mundo homérico y el mundo egeo en el bronce antiguo, que es donde se venía situando en esa "arqueología homérica", de modo que un glorioso pasado micénico no sería sino una elaborada fantasía construida sobre la realidad que se vivía allí en el hierro reciente.

En todos estos estudios se observa que la interacción entre arqueología y análisis literarios ayuda a acercarse a una datación más realista del conjunto de la llíada y de cada una de sus partes, así como a calibrar mejor las alusiones a hechos o costumbres reales, distinguiéndolas de lo que corresponde a la creatividad literaria. 
Se va imponiendo la opinión de que la composición final de la Ilíada es más tardía de lo que se venía considerando hace unas décadas, pero también se observa que en ella se mencionan nombres y objetos que son propios de épocas anteriores a las que se datan las últimas redacciones. Es decir, hay elementos arcaicos que, mediante tradiciones orales, han pervivido y llegado al texto final, aunque no reflejan la vida real del momento en que tuvo lugar la puesta por escrito. Esos elementos arcaicos están integrados con naturalidad en los poemas. La ficción no es historia pero se alimenta de datos reales. De algún modo se sigue comprobando en los poemas homéricos lo que John Chadwick (2003) afirmaba: que no se puede reconstruir la historia desde el mito, pero una vez que conocemos la historia sí que podemos saber cómo ha quedado reflejada en el mito (pp. 84-85).

Dejemos aquí las cuestiones sobre la historicidad de la Ilíada, que no es el tema que ahora nos ocupa, pero sí ayuda a entender cómo se plantea hoy, en el ámbito académico, la relación entre historia y textos clásicos de la antigüedad. Analizar la coherencia de los textos, es decir, preguntarse por el proceso de su composición literaria, y contrastar lo narrado en ellos con el marco de referencias para la época que va dibujando la arqueología, parece una opción razonable por parte de aquel que quiere conocer con mayor precisión cosas interesantes acerca del origen de su cultura.

\section{Biblia e historicidad en la investigación académica actual}

Si un buen número de investigadores se han interesado por la historicidad de la Ilíada, no sorprende que otros - muchos más que para los poemas homéricos- se hayan interesado en la historicidad de la Biblia. Los motivos pueden ser muy variados. En numerosas ocasiones, se trata de cristianos o judíos que quieren conocer mejor algo que les afecta vitalmente. En otras, tal vez en la mayor parte de los casos, esas investigaciones académicas responden a un deseo de llegar a la verdad histórica al margen de cualquier fe. 
De modo análogo a lo que está sucediendo en las cuestiones relacionadas con la historicidad de los textos clásicos, en el momento presente se podría decir que hay dos líneas de investigaciones académicas, distintas pero complementarias, que tienen una incidencia muy directa en el estudio de la Biblia:

- La que se ocupa de la crítica textual y literaria de los textos bíblicos, y a partir de las inconsistencias que se observan en el texto se pregunta por su proceso de composición, circunstancias en que se han escrito e integrado las piezas que lo componen, sentido de esos textos previos cuando eran independientes, qué aportan al quedar integrados en el conjunto, y qué nuevos sentidos reciben leídos como parte de ese conjunto más amplio. Es el ámbito de los estudios literarios e histórico-críticos.

- La que se ocupa especialmente de la historia de Israel o de los orígenes del cristianismo, es decir, la que busca saber lo que pasó en aquel tiempo en aquella área geográfica, a partir de los vestigios de los que se pueda tener conocimiento. Es el ámbito de la historia antigua, con sus metodologías propias.

Pero además de estas líneas de investigación, que siguen abiertas, sería necesario mencionar una tercera, mucho menos desarrollada en la práctica académica que las anteriores, pero que es imprescindible, ya que es la única que permite una comprensión de los textos plenamente coherente con su realidad. Me refiero al hecho diferencial de la Biblia con respecto a cualquier otra obra literaria. Los textos bíblicos son aquellos que, leídos en el conjunto de la Sagrada Escritura y en la fe de la Iglesia, dan testimonio de la Palabra de Dios, viva y eficaz, también hoy y ahora. Por lo tanto, no se puede soslayar una línea de investigación que se mueva en un ámbito teológico, es decir, de una fides quaerens intellectum.

Este hecho diferencial es reconocido por la fe, por eso no sorprende que en el ámbito académico civil nadie se haya planteado trabajar en esta línea. Sin embargo, afrontarlo es ineludible para la teología. Acerca de esta tercera línea de trabajo menos desarrollada, la teológica, es sobre la que vale la pena reflexionar ahora un poco más. 
Me parece que cualquier observador académico del status quaestionis que acabamos de exponer puede estar de acuerdo en que lo que sucede con la cuestión de la Biblia y la historia es lo mismo que sucede con la historicidad de la Ilíada: un camino racional que, apoyándose en los estudios cada vez más abundantes que hay, busca conocer lo mejor posible las interacciones entre esos grandes textos de referencia y el mundo cultural en que surgieron. Ahora bien, la pregunta decisiva es, en el caso de la Biblia, si es suficiente con eso o si faltaría algo. Benedicto XVI, en el prólogo al segundo volumen de su obra Jesús de Nazaret, apunta:

Una cosa me parece obvia: en doscientos años de trabajo exegético la interpretación histórico-crítica ha dado ya lo que tenía que dar de esencial. Si la exégesis bíblica científica no quiere seguir agotándose en formular siempre hipótesis distintas, haciéndose teológicamente insignificante, ha de dar un paso metodológicamente nuevo volviendo a reconocerse como disciplina teológica, sin renunciar a su carácter histórico (Ratzinger, 2011, pp.6-7).

Aunque se refiere al Nuevo Testamento, la afirmación valdría igualmente para el Antiguo.

Tengamos en cuenta que está hablando un experto teólogo alemán, que tiene presente la situación de la exégesis bíblica académica. El contexto es radicalmente distinto al de las lecturas fundamentalistas que difunden los grupos evangélicos en amplias zonas de Latinoamérica o África. En efecto, en los dos últimos siglos, en varios ámbitos académicos se ha avanzado muchísimo en el estudio del proceso de composición de los textos y su marco histórico, y se sigue trabajando en afinar pequeños detalles. La mayor parte de las publicaciones, y también los manuales más difundidos, se ocupan casi exclusivamente de exponer el desarrollo y resultados de estos estudios. No se trata de prescindir de lo que razonablemente se pueda saber por este camino, pero es necesario dar pasos para que la exégesis sea teológicamente relevante. En esta línea, menos explorada, es en la que sería conveniente hacer algunas propuestas. 


\section{Valoración de lo adquirido y propuestas para avanzar}

Cuando las primeras hipótesis de tipo historico-crítico llegaron a la exégesis católica produjeron desorientación, además de por sus propias propuestas -en algunos casos muy distintas a lo que tradicionalmente se mantenía (piénsese, por ejemplo, en lo relativo a la autoría mosaica del Pentateuco)porque en algunos casos estaban imbuidas de prejuicios en contra de toda acción sobrenatural o intervención divina, o lastradas por precomprensiones filosóficas difícilmente conciliables con la fe (es el caso de los presupuestos hegelianos en Wellhausen). De ahí que surgieran, razonablemente, muchas dudas y que no generasen confianza alguna. Lo prudente, y en esta línea se movían las respuestas de la Pontificia Comisión Bíblica a comienzos del siglo XX, era mantenerse a distancia.

Sin embargo, en el momento presente, la mayor parte de los exégetas histórico-críticos no mantienen esos prejuicios ni precomprensiones cerradas a lo sobrenatural, sino que utilizan esa metodología -de ordinario más depurada que en sus fases iniciales- con una intencionalidad histórica y literaria. Hoy se podría decir que esa metodología no presenta obstáculos para la fe, con tal de que uno sea consciente de los ámbitos en los que se mueve y de las limitaciones inherentes a su modo de proceder. De hecho, la Pontificia Comisión Bíblica ha llegado a afirmar, en un documento aprobado por Juan Pablo II, que

El método histórico-crítico es el método indispensable para el estudio científico del sentido de los textos antiguos. Puesto que la Sagrada Escritura, en cuanto "Palabra de Dios en lenguaje humano", ha sido compuesta por autores humanos en todas sus partes y todas sus fuentes, su justa comprensión no solamente admite como legítima, sino que requiere la utilización de este método (Pontificia Comisión Bíblica, 1993, I.A., p.33).

Algo similar podría decirse de la legitimidad de realizar una investigación profunda, con las metodologías adecuadas, sobre la historia antigua de Israel, la figura histórica de Jesús, o los orígenes del cristianismo. Las palabras de Benedicto XVI (2010) en la Exhortación apostólica Verbum Domini son elocuentes: "El hecho histórico es una dimensión constitutiva de la fe cristiana. La historia de la salvación no es una mitología, sino una verdadera 
historia y, por tanto, hay que estudiarla con los métodos de la investigación histórica seria” (n.32).

¿Qué sugerencias se pueden hacer para la docencia y formación de investigadores en las ciencias bíblicas? Sin duda, la clave está en desarrollar las grandes líneas trazadas en Dei Verbum interesándose por la búsqueda del sentido que "expresó el hagiógrafo en cada circunstancia según la condición de su tiempo y de su cultura, según los géneros literarios usados en su época" -lo que reclama la necesaria preparación técnica- y, a la vez, "como la Sagrada Escritura hay que leerla e interpretarla con el mismo Espíritu con que se escribió, para sacar el sentido exacto de los textos sagrados, hay que atender no menos diligentemente al contenido y a la unidad de toda la Sagrada Escritura, teniendo en cuenta la Tradición viva de toda la Iglesia y la analogía de la fe" (n.12).

Es decir, conviene abrir caminos en la línea de lo que Joseph RatzingerBenedicto XVI llama "exégesis canónica" y que consiste en "la lectura de los diversos textos de la Biblia en el marco de su totalidad", y que constituye "una dimensión esencial de la interpretación que no se opone al método histórico-crítico, sino que lo desarrolla de un modo orgánico y lo convierte en verdadera teología" (Ratzinger, 2007, pp. 14-16).

Como punto de partida, en la docencia de la exégesis bíblica, sugeriría comenzar siempre con la lectura atenta del texto y dejar la exposición de las diversas hipótesis para más adelante, una vez que se conozcan con detalle las peculiaridades del texto bíblico, se hayan tocado de cerca sus fracturas en la lógica o en la redacción y se haya adquirido un conocimiento cabal de su mensaje íntegro.

Se trataría de proponer una primera lectura detenida, libro a libro, invitando a reparar en su estructuración y en lo más sobresaliente de su contenido, a la vez que haciendo notar los elementos del texto que, por su estilo, por su parentesco con otros textos antiguos o por su relación con determinados acontecimientos históricos, puedan ser significativos acerca del modo o del momento de su composición o proporcionar claves importantes para su interpretación. 
Más adelante llegará el momento de reflexionar sobre lo que muchas de esas indicaciones, que se han ido señalando invitaban a tomar en consideración. Entonces llegaría el momento de estudiar la historia de la investigación crítica acerca de la composición de los textos para hacerse cargo de las respuestas que se han ido dando a esas cuestiones a lo largo del tiempo y de qué modo estas se han ido ajustando hasta llegar a las hipótesis que se consideran más solventes en el momento actual.

En cualquier caso, si se pretende ayudar a la formación teológica, al hablar de cada una de las etapas en la composición sería conveniente prestar una particular atención a lo que, a la luz de la fe, se aporta en cada momento a la comprensión de los acontecimientos testimoniados en ese texto, es decir, lo que podría denominarse su teología. Asomarse al desarrollo progresivo de la Revelación conduce a observar que la propia Biblia es testimonio de un proceso de reflexión y pausada profundización en los contenidos de las más antiguas tradiciones, en el que se va percibiendo la capacidad que tienen para iluminar sucesivas situaciones históricas.

Por eso, no sería superfluo aprender a escuchar los ecos de los relatos bíblicos en otros textos bíblicos posteriores tanto del Antiguo como del Nuevo Testamento, para captar aquellos aspectos de la Revelación a los que apuntaban, aunque al principio -cuando la manifestación de Dios aún no había recorrido las etapas oportunas- apenas se podía percibir. Lo mismo podría decirse de un acercamiento, aunque fuese necesariamente sintético, a otros ecos más lejanos de ese mismo proceso de recepción, relectura e interpretación realizado en el seno del pueblo de Dios, Israel y la Iglesia, que son aquellos cuya voz se escucha en los textos rabínicos primitivos y en los primeros escritos cristianos.

\section{Conclusiones: Distinción y entrelazamiento de planos entre historia, literatura y teología}

Para ir concretando un poco más algunas ideas, me parece importante tanto para el investigador como para el profesor, así como para el lector y el 
alumno, saber situarse en un plano de trabajo, definir cuál es la metodología adecuada a ese plano y qué tipo de certezas pueden tenerse en él:

- En el plano de la ciencia histórica, la metodología ha de ser exclusivamente racional y a partir de los datos arqueológicos o documentales que se puedan contrastar. La fiabilidad de esos resultados será la que corresponda a las técnicas empleadas y a lo que permitan saber los restos encontrados. Con frecuencia serán hipótesis apoyadas en indicios, de los que es posible que quepan varias interpretaciones. Solo la confluencia de argumentos independientes permitirá ir asentando certezas más fuertes.

- En el plano del estudio de la composición literaria de los textos bíblicos se podría decir que, aunque se llegase a conocer bien lo que el texto podría significar en el contexto histórico en que se compuso, el sentido encontrado remite al pasado, no al presente. Puede dar pistas sobre cómo es Dios, cómo se manifiesta en la historia, qué enseña sobre el mundo o el ser humano, y muchas cosas más, pero en este plano no se llega a escuchar la Biblia como palabra actual.

- Por eso, para atender plenamente a todo lo que el texto tiene que decir al lector, nunca debe faltar el tercer plano del que hemos hablado. La teología puede y debe entrelazarse con los dos anteriores. Es la fides quaerens intellectum que indaga y reflexiona sobre las pistas históricas y literarias de los textos, busca integrarlos armónicamente con lo que conoce a la luz de la plenitud de la revelación y, dentro de ese marco que proporciona la fe de la Iglesia, permite escuchar la Palabra de Dios que habla hoy y ahora.

En síntesis, se trata de poseer y utilizar las herramientas intelectuales oportunas para realizar una lectura de la Biblia en la que se sinteticen armónicamente los resultados válidos de los estudios histórico-críticos y la imprescindible dimensión teológica, sin perder de vista la unidad de la Escritura, la Tradición de la Iglesia y la analogía de la fe. 


\section{Referencias}

Ahlström, G. W. (1993). The History of Ancient Palestine from the Palaeolithic Period to Alexander's Conquest. Sheffield, Reino Unido: Sheffield Academic Press.

Benedicto XVI (2010). Exhortación Apostólica "Verbum Domini". Ciudad del Vaticano: Libreria Editrice Vaticana.

Borg, M. J. (1994). Meeting Jesus Again for the First Time. The Historical Jesus \& the Heart of Contemporary Faith. San Francisco, EE.UU.: Harper.

Campbell Jr., E. F. (1998). A Land Divided: Judah and Israel from the Death of Solomon to the Fall of Samaria. En M. D. Coogan (ed.), The Oxford History of the Biblical World (pp. 206-241). Oxford, EE.UU.: Oxford University Press.

Chaney, M. L. (1983). Ancient Palestinian Peasant Movements and the Formation of Premonarchic Israel. En D. N. Freedman \& D. F. Graff (eds.), Palestine in Transition. The Emergence of Ancient Israel (pp. 39-90). Sheffield, Reino Unido: Continuum International Publishing Group.

Chadwick, J. (2003). The Mycenaean World. Cambridge, Reino Unido: Cambridge University Press.

Collins, J. J. \& Sterling, G. E. (eds.) (2001). Hellenism in the Land of Israel. Notre Dame, EE.UU.: University of Notre Dame Press.

Crossan, J. D. (1991). The Historical Jesus. The Life of a Mediterranean Jewish Peasant. San Francisco, EE.UU.: Harper.

Crossan, J. D. (1994). The Essential Jesus. Original Sayings and Earliest Images. San Francisco, EE.UU.: Harper.

Dalley, S. (2004). Recent Evidence from Assyrian Sources for Judaean History from Uzziah to Manasseh. Journal for the Study of the Old Testament, 28, 387-401

Darshan, G. (2013). The biblical account of the post-diluvian generation (Gen 9:20-10:32) in the light of Greek genealogical literature. Vetus Testamentum, $63,515-535$.

Davies, Ph. R. (2008). Memories of Ancient Israel: An Introduction to Biblical History - Ancient and Modern. Louisville: Westminster John Knox.

Dickinson, O. T. P. K. (2010). Was there really a Trojan War? The Anglo-Hellenistic Review, 41, 18-22. 
Downing, F. G. (1988). Christ and the Cynics: Jesus and Other Radical Preachers in First-Century Tradition. Sheffield, Reino Unido: Sheffield Academic Press.

Doran, R. (2011). The Persecution of Judeans by Antiochus IV: The Significance of "Ancestral Laws". En Harlow, D. C. \& Hogan, K. M. \& Goff, M. \& Kaminsky, J. S. (eds.), The "Other" in Second Temple Judaism: Essays in Honor of John J. Collins (pp. 423-433). Grand Rapids, EE.UU.: Eerdmans.

Edelman, D. V. (1993). The History of Ancient Palestine. Minneapolis, EE.UU.: Fortress.

Faust, A. (2000). The Rural Community in Ancient Israel during Iron Age II. Bulletin of the American Schools of Oriental Research, 317, 17-39

Faust, A. \& Weiss, E. (2005). Judah, Philistia, and the Mediterranean World: Reconstructing the Economic System of the Seventh Century B.C.E. Bulletin of the American Schools of Oriental Research, 338, 71-92

Finkelstein, I. (1996). The Territorial-Political System of Canaan in the Late Bronze Age. Ugarit-Forschungen, 28, 221-255.

Finkelstein, I. \& Mazar, A. (2007). The Quest for the Historical Israel: Debating Archaeology and the History of Early Israel. Atlanta, EE.UU.: Society of Biblical Literature.

Galil, G. (2001). A Re-Arrangement of the Fragments of the Tell Dan Inscription and the Relations between Israel and Aram. Palestine Exploration Quarterly, 133, 16-21.

Grabbe, L. L. (ed.) (2008). Israel in Transition: From Late Bronze II to Iron IIa (c. 1250850 B.C.E.). Volume 1: The Archaeology. Nueva York, EE.UU.: T \& T Clark.

Grabbe, L. L. (ed.) (2010). Israel in Transition: From Late Bronze II to Iron IIa (c. 1250-850 B.C.E.). Volume 2: The Texts. New York, EE.UU.: T \& T Clark.

Grethlein, J. (2008). Memory and Material Objects in the Iliad and the Odyssey. Journal of Hellenic Studies, 128, 27-51.

Hallo, W. W. (ed.) (2002). The context of Scripture. Leiden, Holanda: Brill.

Heltzer, M. (2008). The Province Judah and the Jews in Persian Times. Tel Aviv, Israel: Archaeological Center Publication.

Horsley, R. A. (2003). Jesus and Empire. The Kingdom of God and the New World Disorder. Minneapolis, EE.UU.:Fortress Press. 
Joffe, A. H. (2002). The Rise of Secondary States in the Iron Age Levant. Journal of Economic and Social History of the Orient, 45, 425-467.

Kelly, A. (2006). Homer and history: Iliad 9.381-4. Mnemosyne, 59, 321-333.

Kitchen, K. (2004). The Victories of Merenptah, and the Nature of their Record. Journal for the Study of the Old Testament, 28, 259-272

Knoppers, G. N. (2003). Shem, Ham and Japheth: the universal and the particular in the genealogy of nations. En Graham, M. P. \& McKenzie, S. L. \& Knoppers, G. N. (eds.), The Chronicler as theologian: essays in honor of Ralph W. Klein (pp. 13-31). New York, EE.UU.: T \& T Clark.

Lemche, N. P. (1985). Early Israel: Anthropological and Historical Studies on the Israelite Society Before the Monarchy. Leiden, Holanda: Brill.

Lemche, N. P. (1998). The Israelites in History and Tradition. Louisville, EE.UU.: Westminster.

Lipschitz, O. \& Oeming, M. (eds.) (2006). Judah and the Judeans in the Persian Period. Winona Lake, EE. UU.: Eisenbrauns.

Liverani, M. (2003). Oltre la Bibbia. Storia antica di Israele. Roma - Bari: Laterza.

Mack, B. L. (1993). The Lost Gospel: The Book of Q and Christian Origins. San Francisco, EE. UU.: Harper.

Maeir, A. M. (2014). Khirbet Qeiyafa in its Regional Context: A View From Philistine Gath. En Schroer, S. \& S. Münger (eds.) Khirbet Qeiyafa in the Shephelah (pp. 61-72). Fribourg, Suiza: Academic Press.

Meier, J. P. (1998-2017). Un judio marginal. Nueva visión del Jesús histórico (vol. I, II/1, II/2, III, IV y V). Estella, Espańa: Verbo Divino.

Neill S. \& Wright, N. T. (1988). The Interpretation of the New Testament 1861-1986. Oxford, EE. UU.: Oxford University Press.

Petrakis, V. P. (2006). History versus the Homeric "Iliad": A View from the Ionian Islands. The Classical World, 99, 371-396.

Pontificia Comisión Bíblica (1993). La interpretación de la Biblia en la Iglesia. Madrid, Espańa: PPC.

Ratzinger, J. - Benedicto XVI (2007). Jesús de Nazaret. Volumen I. Desde el Bautismo a la Transfiguración. Madrid, España: La Esfera de los libros. 
Ratzinger, J. - Benedicto XVI (2011). Jesús de Nazaret. Volumen II. Desde la Entrada en Jerusalén hasta la Resurrección. Madrid, España: Encuentro.

Sanders, E. P. (2001). La figura histórica de Jesús. Estella, España: Verbo Divino.

Smith, M. (1978). Jesus the Magician. New York, EE. UU.: Harper \& Row.

Soggin, J. A. (2002). Storia d'Israele dalle origini a Bar Kochbà. Brescia, Italia: Paideia.

Segalla, G. (1993). La “terza” ricerca del Gesù storico: Il Rabbi ebreo di Nazaret e il Messia crocifisso. Studia Patavina, 30, 463-511.

Thompson, Th. L. (1992). Early History of the Israelite People. From the Written of Archaeological Sources. Leiden, Holanda: Brill.

Theissen, G. (1985). Sociología del movimiento de Jesús. El nacimiento del cristianismo primitivo. Santander, España: Sal Terrae.

Theissen, G. (1988). La sombra del Galileo. Las investigaciones históricas sobre Jesús traducidas a un relato. Salamanca, Espańa: Sígueme.

Theissen, G. (2003). El Nuevo Testamento: historia, literatura, religión. Santander, España: Sal Terrae.

Twelftree, G. H. (1993). Jesus the exorcist: a contribution to the study of the historical Jesus. Peabody, EE.UU.: Hendrickson.

Varo, F. (1995). El marco histórico del Antiguo Testamento. Perspectivas actuales. Scripta Theologica, 27, 751-788.

Varo, F. (2013). Historia social y religiosa de Israel en los tiempos bíblicos. En Carbajosa, I. \& González Echegaray, J. \& Varo, F., La Biblia en su entorno pp. 155-409. Estella, España: Verbo Divino.

Varo, F. (2015). El Antiguo Testamento en el Concilio Vaticano II. Scripta Theologica, 47, 155-175.

Vermes, G. (1996). La religión de Jesús el judío. Barcelona, España: Anaya \& Mario Muchnik.

Whitelam, K. L. (1996). The Invention of Ancient Israel: The Silencing of Palestinian History. Londrés, EE. UU.: Routledge.

Witherington, B. (1994). Jesus the Sage. The Pilgrimage of Wisdom. Minneapolis, EE. UU.: Fortress Press. 
Fe, razón y teología en torno a la historia bíblica

Wright, N. T. (1996). The Original Jesus. The Life and Vision of a Revolutionary. Grand Rapids, EE.UU.: Eerdmans. 